\title{
TERCES, PREDICACIÓ I RECAPTACIÓ DE LA CROADA DURANT EL REGNAT DE FERRAN D'ANTEQUERA
}

\author{
ROSER SALICRÚ I LLUCH \\ Institució Milà i Fontanals \\ (CSIC, Barcelona)
}

Més enllà de les notícies que en dóna la part inèdita de la crònica d'Álvar García de Santa María' i d'alguns fragments que en va publicar Carriazo $^{2}$, les referències historiogràfiques al fet que el Papa atorgués butlles de croada, a la concessió d'indulgències i de terces amb posterioritat a la campanya d'Antequera i durant el regnat de Ferran I, i als problemes derivats de la seva recaptació són molt escasses ${ }^{3}$.

Segons Suárez Fernández, la primera concessió de terces de Benet XIII a Joan II de Castella, amb validesa de tres anys, data del primer d'abril de $1407 \mathrm{i}$, el 1410, fou allargada fins el 1412, pròrroga que s'estengué a Caterina de Lancàster, a Ferran d'Antequera i a la seva muller, Elionor

\footnotetext{
'D. FERro, Le parti inedite della "Crónica de Juan II" di Álvar Garcia de Santa María, Venècia, Consiglio Nazionale delle Ricerche (Gruppo Studi d'Hispanistica), 1972, pp. 153-155. 57.

2J. de M. Carriazo Arroquia, Anecdotario sevillano del siglo XV, Sevilla, 1947, pp. 55-

${ }^{3}$ Només a tall d'exemple podem dir que la History of the Crusades ni ho esmenta $(\mathrm{Ch}$. J. BISHKO, The Spanish and Portuguese Reconquest, 1095-1492, dins H.B. HAZARD (Ed.), The Fourteenth and Fifteenth Centuries, vol. III, pp. 443-448, dins K.M. SETTON (Ed.), A History of the Crusades, Wisconsin, The University of Wisconsin Press, 1975), o que una monografia com la de N. HOUSLEY, The later crusades, 1274-1580. From Lyons to Alcazar, Oxford, Oxford University Press, 1992, que tanmateix dedica un capitol al període 1274-1415, es limita a aventurar que, "segurament", el Papa concedí les terces a les campanyes de 1407 i 1410 "tal com de costum es feia cada vegada que els monarques castellans emprenien les hostilitats contra Granada" (p. 286).

"Anuario de Estudios Medievales", 29 (1999)
} 
d'Alburquerque. Sembla que, aleshores, la concessió no fou renovada, per bé que, al llarg de 1413, els castellans seguiren cobrant les terces i, per això, el 1414 , el Papa Luna retirà a Caterina de Lancàster la potestat de recaptar-les que detenia indegudament ${ }^{4}$. Tanmateix, davant de les protestes castellanes al-legant que les terces eren necessàries per prosseguir la guerra contra els infidels, a la primeria de 1414 el Pontífex accedí, de nou, a renovar-li la concessió, encara que imposant-li diverses condicions: la regent de Castella hauria de declarar, en primer lloc, que el 1413 s'havien cobrat indegudament; totes les concessions iure hereditario sobre les terces serien anul-lades; el 1414 es podrien percebre, tot i que no hi hagués guerra entre Castella i Granada, per motiu de la sequera i de la fam; però, un cop transcorregut aquest any, haurien de destinar-se a l'obra de les esglésies ${ }^{5}$. Per tant, si l'1 d'abril de 1415 no hi havia guerra amb Granada, el privilegi quedaria anul-lat; i, com que no n'hi hagué, el 1415, a desgrat de les successives protestes de la reina Caterina, Benet XIII ordenà als bisbes que apliquessin, de nou, l'impost a les esglésies, i es negà a tornar-lo a concedir a la Corona ${ }^{6}$.

Malauradament, però, Suárez Fernández no ens aporta cap dada relativa a Ferran d'Antequera i a la Corona d'Aragó.

Les parts inèdites de la crònica de García de Santa María narren extensament -dins l'any 1414 però no necessàriament fent-hi sempre referència, perquè alguns dels fets que hi són relacionats es remunten a l'època de la regència anterior a l'entronització de Ferran d'Antequera com a monarca catalanoaragonès- «como el Papa otorgo cruzada e como el rey de Aragon siendo infante e tutor del rey de Castilla lo mando coger por el reino, e el gran daño que dende vino a Castilla» ${ }^{7}$.

Sobretot pel que fa als problemes que, segons García de Santa María, s'originaren en la recaptació, una lectura atenta del seu relat ens permetrà trobar molts punts de concordança amb les notícies que ens aporta, ja durant el regnat de Ferran I, la documentació catalanoaragonesa:

${ }^{4}$ L. SUÁREZ FERnÁNDEZ, Castilla, el Cisma y la crisis conciliar (1378-1440), Madrid, CSIC, 1960, p. 73 i nota 1 , i document 89 de l'apèndix documental, pp. 294-298.

${ }^{5} \mathrm{Cf}$. ibidem, p. 73 i nota 2 , i documents 87 i 88 de l'apèndix documental, pp. 293-294.

${ }^{6} \mathrm{Cf}$. ibídem, p. 74 i notes 3 i 4.

${ }^{7} \mathrm{D}$. FERRO, Le parti inedite, pp. 153-155. 
E agora (...) la historia (...) contara como el Papa otorgo cruzada e como el rey de Aragon siendo infante e tutor del rey de Castilla lo mando coger por el reino, e el gran daño que dende vino a Castilla.

$\mathrm{El}$ infante don Fernando antes que fuesse rey de Aragon, (...) quando iba a la guerra de los moros, (...) llevaba dos pendones de la cruzada los quales dezian que le envio el Padre Santo con indulgencia para los que guardassen la cruzada e diessen de lo suyo para la dicha guerra, de los quales era alferez, por mandado del dicho infante, Fernan Arias de Sayavedra. E quando se envio por estos pendones bien es verdad que con zelo e con buena intencion se fizo e se movio a lo demandar por menguar la secta de los moros e por acrecentar la fe catolica de Jesucristo, e lo que alli se diesse, se guardasse, e se pusiesse en deposito puramente para lo que lo dieron los que con buena intencion lo diessen. Mas segun por la manera se fizo, sintiosse en ello muy gran daño, que fue muy despechada la tierra e no quedo provecho ninguno para lo que ello se daba. El infant don Fernando, movido a bien e con buena intencion teniendo que por esta cruzada abria muy grande ayuda para proseguir las guerras de los moros, plugole mucho e mando fazer thesoreros a frailes de monesterios ansi de la orden de Santo Domingo, como de la orden de San Francisco y de las otras ordenes de abitos blancos en toda la provincia de su regimiento, e cada uno destos en el arçobispado e obispado por do iban, andaban predicando los perdones que abian los que fuessen en la cruzada e los que diessen dozientos e quarenta maravedis, que era la menor cantia que obiessen indulgencia a culpa e a pena, maguer que otras abia de cinco mil e otras de mas, segun fuesse la persona. E como las buenas gentes destos reinos son movidos a caridad cobdiciando de ser perdonados de sus pecados, movianse mucho a dar de lo suyo. El que no tenia dineros daba vacas o obejas, o pan, o vino, azeite, o ropas e armas, plata e oro e muchas joyas cada uno segun que mejor podia. E los frailes no se emperezaban a lo tomar, e tomaban estas cosas, e vendianlas, e fazian dellas mucho dinero. E como quiera que recibian trabajo en andar predicando, e coxiendolo poco a poco con todo esto bien se mantenian dello, que doquier que ellos podian fallar gallinas e perdizes, no comian vacas ni sardinas. E segun su buena intencion del infante bien penso que lo no podia el mejor fiar que era de hombres religiosos, e guardarian bien el servicio de Dios e su conciencia, maguer que por la cuenta no parecia ansi despues que el fraile que recaudo un cuento de maravedis no dio la mitad, e de todo lo al passo en costa de comer, e predicadores, e de thesoreria que llevaban de cada casa un florin de chancilleria, e otras muchas burlas que en ello fizieron segun que mejor lo saben los contadores mayores del rey de las sus quentas que les tomaron las cuentas. E lo al que sobre todo se gasto, no en lo que fue dado. E como quiera que el infante don Fernando lo mando coger en su provincia, la noble reina doña Catalina, tutora del rey su hijo, mando que se non cogiesse en la suya, e fue muy bien probado que fizo bien, sintiendo el daño que dello podia venir segun vino. E como quiera que muchas gentes 
ponian en ello culpa al infante diziendo que fue movido a cobdicia en el coger desta cruzada por tener dineros para proseguir el su negocio de los reinos de Aragon, no fue esta su intencion, antes teniendo que abiendo tomado la possession de sus reinos que vernia a proseguir la dicha guerra de los moros e tenia de que se cumplir. Pero el tiempo se siguio de otra manera segun que abedes oido e oiredes adelante porque la guerra no se pudo fazer, e lo que della se cogio obo asaz lugares do lo despendiesse. E como quiera que en los dineros obo mal recaudo para los que los dieron con sana e buena intencion al fin que los dieron los son contados ante Dios, ca sin duda segun nuestra fe la mayor perdonança que los homes en esta vida pueden aber es ir en cruzada contra los enemigos de la fe, e dan de sus dineros para ir contra ellos en cruzada. E segun dize la primera partida van asueltos a culpa e a pena de sus pecados a la gloria del paraiso los que ende mueren. E como quiera que sea ansi verdad por ver muchos de los que tomaron las indulgencias el mal recaudo que se puso en esta cruzada en los dineros della, muchos perdieron la fe de las indulgencias, e por ende los reyes quando mandan coger la cruzada deben mandar poner en ello buen recaudo porque se sepa todo lo que en aquello se despiende e por que se da, e aun es les gran carga de conciencia quando de otra guisa lo fazen ${ }^{8}$.

Els problemes $\mathrm{i}$ abusos en la recaptació de les indulgències que descriu García de Santa María s'estenen, per tant, més enllà de l'època que Ferran tan sols era regent de Castella, i és per això que queden amplament testimoniats en la documentació catalanoaragonesa del seu regnat.

Aquesta documentació també posa de manifest que, com a monarca catalanoaragonès, Ferran I va intentar aconseguir de Benet XIII la concessió d'indulgències per a tots aquells que l'ajudessin a lluitar "contra els infidels de la secta de Mahomet" en les mateixes condicions que les tenia concedides el seu nebot, Joan II, per al regne de Castella9.

No sabem pas que Ferran I se'n sortís, tot i que, de fet, al llarg dels quatre anys del seu breu regnat hi ha diversos indicis que evidencien que el monarca Trastàmara no abandonà mai la idea de reprendre la guerra de Granada i que alimentà constantment l'esperança de poder fer-ho, cosa que,

\footnotetext{
${ }^{8} \mathrm{Cf}$. ibidem.

${ }^{9}$ ACA, C., reg. 2359, f. 109r. 1413, febrer, 9. Barcelona. Súplica de Ferran I a Benet XIII "quatenus sancte unice crucis auxilium sit nobis et cunctis Christi ffidelibus nobiscum euntibus in exterminium et conculcationem dicte nepharie gentis saracenice colentis sua damptatissima cecitate sectam dampnatissimam Mahometi dignemini misericorditer indulgere quemadmodum serenissimo principi domino Ioanni regi Castelle, nepoti nostro carissimo. ex causa predicta concessa extitit et donata".
} 
quan morí, el 1416, a Igualada, camí de Castella, probablement estava a punt d'aconseguir ${ }^{10}$.

Però sí que sabem que, des de la Corona d'Aragó, Ferran d'Antequera continuà vetllant per les almoines que, a Castella sí, es recaptaven per la croada.

Així, per exemple, el 5 de març de 1413, donava potestat als frares «Iohanni Conchiensi de Furno Novo, ordinis minorum», i «Iohanni de Villatoro, priori murciensis ordinis predicatorum ac ministro Sancte Trinitatis civitatis murciensis», perquè, d'acord amb els poders que els havia atorgat una carta de Joan II de Castella expedida a Conca el 3 de febrer de 1412, també poguessin recaptar, a les terres de la diòcesi de Múrcia que eren de jurisdicció catalanoaragonesa, "peccunias et alia quecumque quas et que persone quevis dederint vel legaverint crucis predicationi quam sanctissimus dominus noster Papam concessit eidem regi in guerra quam habet cum infidelibus perfidis crucis et fidei hostibus sarracenis»"

Per bé que les notícies que he pogut recollir sobre els problemes en la recaptació de les indulgències siguin poques, concorden perfectament amb la crònica de García de Santa María pel que fa a les acusacions d'abusos dels recaptadors i a llurs negatives de presentar els comptes, escudant-se, a voltes, al seu torn, en acusacions en contra del monarca pel fet que la inexistència de guerra contra Granada no el legitimava a exigir-les.

Sabem que, a l'inici d'abril de 1413 , Ferran I ja s'adreçà al papa Benet XIII per queixar-se del fet que diverses persones eclesiàstiques $\mathrm{i}$ religioses, algunes exemptes, algunes altres no, de les que anteriorment havien administrat, a Castella, els diners de la Santa Croada, aleshores es negaven a passar comptes i pretenien quedar-se amb els diners que havien recaptat. Segons el monarca catalanoaragonès, s'emparaven en el parer d'alguns lletrats que interpretaven que les indulgències que el Pontífex havia concedit, durant un trienni, per fer la guerra contra els infidels, ja no tenien vigència, perquè no hi havia guerra amb el sultanat nassarita. Davant d'aquest fet, Ferran d'Antequera demanà a Benet XIII que hi proveís i que

\footnotetext{
${ }^{10}$ Vegeu R. SALICRÚ I LLUCH, Posibilidades de reanudación de la guerra de Granada a finales del reinado de Fernando I de Aragón (1415-1416), dins La Peninsula Ibérica en la era de los descubrimientos (1391-1492). Actas III Jornadas Hispano-Portuguesas de Historia Medieval. Sevilla 25-30 de noviembre 1991. Sevilla. Junta de Andalucía-Universidad. 1997, vol. II. pp. 1437-1452, o idem, El sultanat de Granada i la Corona d'Aragó, 1410-1458. Barcelona, Publicacions de l'Abadia de Montserrat-CSIC, 1998. pp. 95-112.

"ACA, C., reg. 2397, f. 72r-v. 1413, març. 5. Barcelona.
} 
obligués tots aquests eclesiàstics a retre comptes i a restituir els diners que haguessin recaptat fins aleshores ${ }^{12}$.

En la mateixa línia, a la darreria de maig de 1413, Ferran I també va demanar al mestre general de l'orde de predicadors - i recordem que, en efecte, segons el cronista, Ferran havia fet «thesoreros a frailes de monesterios ansi de la orden de Santo Domingo, como de la orden de San Francisco y de las otras ordenes de abitos blancos en toda la provincia de su regimiento»- que ordenés als administradors dels diners de les diverses indulgències que Benet XIII havia concedit, a súplica de Ferran i de Caterina de Lancàster, als cristians que fessin donacions en favor de les gents armades contra els infidels i que estiguessin sota la seva obediència, que presentessin els comptes d'allò que havien rebut $\mathrm{i}$ administrat $\mathrm{i}$ que restituïssin el romanent a la Corona ${ }^{13}$.

I, a la fi de novembre d'aquell mateix any, 1413, Ferran encara adreçava una nova súplica al Papa per demanar-li, aquesta vegada, que concedís llicència al bisbe de Cartagena per empresonar els eclesiàstics que malgastaven, en benefici propi - i altra vegada d'acord, per tant, amb el text de García de Santa María-, els diners que recaptaven de la croada, almenys mentre continuessin negant-se a presentar els comptes d'allò que haguessin rebut i no li ho entreguessin. A la vegada, Ferran també demanà al Pontífex que li concedís una llicència que permetés que els oficials reials poguessin capturar els frares que no volguessin retre comptes; un cop fossin presos, el monarca es comprometia a fer-los lliurar a llur respectiu diocesà en el termini que el Papa volgués establir ${ }^{14}$.

En darrer terme, el 4 de juny de 1415 , des de València, Ferran I encara demanava al justícia de Daroca, Pere Ram, que lliurés a Rodrigo de Palencia els béns vacants i les escriptures del difunt fra Martín de Bellota. Rodrigo tenia poders per recaptar els maravedisos de la croada al bisbat de Sigüenza, i els béns del frare difunt pertanyien a la seva col·lectoria ${ }^{15}$.

Però els problemes en la recaptació de la croada que recull García de Santa María no es produïren pas, exclusivament, en terres castellanes,

\footnotetext{
${ }^{12} \mathrm{ACA}, \mathrm{C}$. , reg. 2384, f. 5v. 1413, abril, 6. Barcelona.

${ }^{13} \mathrm{ACA}, \mathrm{C}$. , reg. 2397, f. 91v. 1413, maig, 24. Barcelona.

${ }^{14} \mathrm{ACA}, \mathrm{C}$, reg. 2403, f. 147v. 1413, novembre, 27. Lleida.

${ }^{15} \mathrm{ACA}, \mathrm{C}$., reg. 2376 , f. 53v. 1415 , juny, 4. València.
} 
puix que alguns testimonis documentals ens mostren que, almenys en dues ocasions, n'hi hagué també en terres valencianes.

Abans de mitjan mes de març de 1413, fra Antoni de Thuicella, de l'orde de predicadors, tresorer de la croada al marquesat de Villena, havia fet saber a Ferran que, quan el seu lloctinent, fra Rodrigo de la Colunya, arribà a la vila de Biar, on havia anat a predicar la croada a requesta del vicari del lloc, l'oficial del bisbe de València a Xàtiva, «quaix ab alguna manera de abolot, concità lo poble (...) contra lo dit ffrare Rodrigo, donant entenent que lo temps de la croada era passat, dient moltes altres coses desonestes». En conseqüència, el rei, que no entenia per què totes aquestes mentides no havien estat castigades i que assegurava que "el temps de la croada" durava fins el 8 de maig de $1413^{16}$, s'adreçà als jurats i prohoms de Biar per ordenar-los que elegissin dues persones de bé de llur universitat en poder de les quals poguessin ser dipositades totes les monedes recaptades a la vila i a la comarca per raó de la Santa Croada, i que els les fessin custodiar, ben guardades, fins que ell es desplacés al regne de València. Aleshores, ell mateix ja s'encarregaria de discutir l'afer amb el bisbe de València i de proveir-hi ${ }^{17}$.

A Aiora i a Capdet, en canvi, el que succeïa era ben diferent. Tot i que, si fem cas a les paraules del monarca que recull la carta anterior, aleshores el temps de recaptació de la croada ja hagués expirat, a la primeria de setembre de 1413 encara hi havia diversos donatius i prometences que no s'havien collit i que continuaven en mans d'aquells que n'havien fet ofrena. Per posar-hi solució, Ferran hi proveí de manera semblant que en el cas de Biar: ordenà als jurats i prohoms d'Aiora i Capdet que elegissin una persona bona i fiable perquè fes la col-lecta de tots els donatius que hi hagués pendents i perquè els conservés, sota bona guarda, fins a nova ordre. Aquesta vegada, tanmateix, volia que, un cop haguessin recaptat tots els diners, li certifiquessin a quina quantitat ascendien ${ }^{18}$.

La documentació catalanoaragonesa ens aporta, en darrer terme, algunes referències a les terces $\mathrm{i}$ als donatius fets a la croada que donen testimoni tant del fet que, com dèiem abans, a Castella, el 1413, les terces

\footnotetext{
${ }^{16}$ "com nós siam cert e certifficam encara a vosaltres que lo temps de la dita croada dura e durarà encara fins al VIII jorn de maig primer vinent".

${ }^{17} \mathrm{ACA}, \mathrm{C}$, reg. 2359, ff. 132v-133r. 1413, març, 15. Barcelona.

${ }^{18} \mathrm{ACA}, \mathrm{C}$., reg. 2421 , f. 104v. 1413, setembre, 2. Setge de Balaguer.
} 
seguiren recaptant-se, com de la desviació dels diners recaptats de la seva finalitat originària, la guerra de Granada. Però, a la vegada, aquestes referències també fan palès que, almenys en aquests casos, tot i que Ferran I es considerés legitimat per desviar els diners, ho féu amb finalitats benèfiques i pietoses, prèvia sol-licitud de consentiment i dispensa papals, i que els motius adduits foren els mateixos que, el 1414, permeteren que Benet XIII concedís de nou a la Corona la percepció de les terces encara que no hi hagués guerra entre Castella i Granada: la sequera i la fam.

D'aquesta manera, per exemple, a la primeria de març de 1413 el monarca suplicà al Pontífex que atorgués dispensa a diverses religioses a les quals Joan II de Castella havia assignat una certa quantitat de blat sobre les terces de l'ardiaconat de l'església toledana. Les religioses que Ferran anomena a la carta eren Agneta, abadessa del monestir de Santa Clara de Toledo; la seva germana, Isabel; Teresa de Ayala, prioressa de Santo Domingo el Real; i Maria, filla del rei Pere I de Castella. Ferran assegurava que el blat només seria destinat al proveïment de les monges, $i$ afegia que, fins aleshores, no l'havien pogut rebre perquè hi obstava una butlla que el reservava al sosteniment de la guerra contra els infidels ${ }^{19}$.

$\mathrm{Si}$, en aquest cas, la petició del monarca catalanoaragonès es referia, només, a un cas particular, a l'inici de setembre de 1413, en canvi, suplicà a Benet XIII, però ara amb caràcter general, que permetés que les terces que havia concedit en socors dels cristians castellans que anessin a combatre els pèrfids agarens i que no es podien invertir en cap altre ús sense llicència papal poguessin ser invertides, durant aquell any, tant en almoines i sufragis en favor de religiosos i persones miserables com en altres usos semblants. El monarca al·legava, perquè el Papa hi accedís, la gran esterilitat i fam que patia el regne de Castella ${ }^{20}$.

Però la carestia de blat a Castella no fou només excusa per desviar el producte de les terces de la seva finalitat primigènia, puix que Ferran d'Antequera l'emprà, també, per reconduir cap a altres fins els donatius fets a la croada.

A la primeria de juny de 1413 -i quan, per tant, com ja hem vist, en teoria ja havia acabat el temps de la croada-, Ferran tornava a buscar el

\footnotetext{
${ }^{19} \mathrm{ACA}, \mathrm{C}$. , reg. 2382, f. 30r. 1413, març, 10. Barcelona.

${ }^{20} \mathrm{ACA}, \mathrm{C}$, reg. 2381 , f. $38 \mathrm{r}$. 1413 , setembre, 4. Setge de Balaguer. Amb la mateixa referència $i$ data hi ha també registrada una petició d'intercessió adreçada a Andreu Bertran, almoiner del Papa, i al procurador reial a la cúria romana, Lope Gonzalo de Olmedo.
} 
beneplàcit papal per desviar els beneficis de la predicació de la croada, encara que, aquest cop, prometia considerar-los i usar-los, només, com a préstec $\mathrm{i}$, per tant, restituir-los. El monarca adduïa, per un costat, que al regne de Castella hi havia gran carestia de blat $i$, per un altre, que els rèdits reials no eren suficients per comprar el pa que feia falta per proveir els castells de la frontera de Granada. En aquesta ocasió, per tant, no pretenia pas destinar els ingressos de la croada a una finalitat gaire allunyada d'aquella per la qual havien estat recaptats, perquè, al capdavall, si els castells de frontera no es podien abastar de blat es corria el perill que es despoblessin i que això ocasionés danys irreparables al regne de Castella. En conseqüència, demanava llicència a Benet XIII perquè els diners i béns oblats poguessin servir per comprar pa i altres vitualles per proveir les fortaleses de la frontera castellanogranadina, tot i que prometia, com hem dit, que tant la reina de Castella com ell mateix farien reparar íntegrament a la croada o al seu tresorer tot allò que en rebessin amb aquest pretext ${ }^{21}$.

Tot plegat constitueix una mostra més de fins a quin punt, al llarg del seu regnat, Ferran d'Antequera seguí amatent les qüestions castellanes i atengué la seva tasca de regent de Castella i de tutor del seu nebot, Joan II.

Des de la Corona d'Aragó, Ferran I intercedí més sovint del que semblava o del que s'havia volgut fer veure en els afers castellans, fos per iniciativa pròpia o fos perquè, també des de Castella, se seguí apel-lant a la seva condició. I no hi ha dubte que la qüestió granadina, que l'infant d'Antequera considerà sempre en un parèntesi provisional i forçat i no pas volgut ni voluntari, fou una de les que estigué sempre en el rerefons de molts dels seus continuats contactes amb Castella.

\footnotetext{
${ }^{21}$ ACA, C., reg. 2383, f. 49v. 1413, juny, 10. Barcelona. Hi ha registrada una carta de la mateixa data adreçada a Lope Gonzalo, procurador reial a la cúria romana, per demanar-li intercessió (ACA, C., reg. 2383, ff. 49v-50r) i una altra, escrita tres dies abans i dirigida a l'almoiner papal, Andreu Bertran, per recomanar-li Gonzalo de Celada, tresorer de la santa croada a les diòcesis de Badajoz i de Coria, que anava a la cúria per diversos afers relacionats amb la croada - $\mathrm{i}$ que, per tant, probablement era l'encarregat de lliurar la petició a Benet XIII- (ACA, C., reg. 2382, f. 84r. 1413. juny, 7. Barcelona).
} 


\begin{abstract}
RÉSUMÉ
Après la campagne d'Antequera et sous le règne de Ferdinand Ier, en dehors des informations fournies par la partie inédite de la chronique d'Álvar García de Santa María, on disposait de peu de données relatives à la délivrance d'indulgences et de tercias, et concernant leur perception. Cet article présente quelques documents nouveaux qui complètent les descriptions de la chronique, et apporte un autre témoignage de l'interêt que le monarque continua à manifester pour les affaires de Castille et de Grenade même après son intronisation.
\end{abstract}

\title{
SUMMARY
}

Beyond those provided by the unedited sections of the chronicle of Álvar Garcia de Santa María, after the Antequera campaign and during the reign of Fernando I we haved very scarce data on the granting of indulgences and tercias and on their collection. This article presents some new documents that complete the descriptions offered in the chronicle, and constitutes another instance of the sustained interest for the kingdom of Castile and for the Granadan affairs during his short rule. 